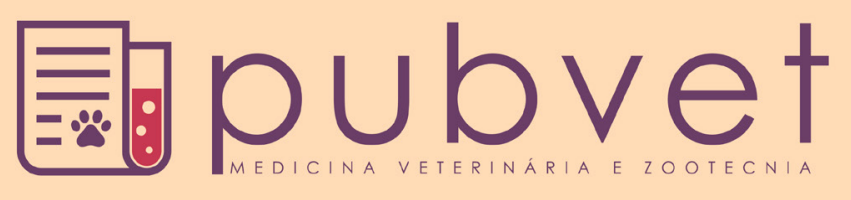

HTTP://DX.DOI.ORG/10.22256/PUBVET.V11N4.363-370

\title{
Lipoma subcutâneo abrangendo as regiões cervical e peri-auricular de um canino: Relato de caso
}

\author{
Francisco Lima Silva ${ }^{1}$, Thiago Sousa da Silva ${ }^{2 *}$, Fernando Barbosa de Sousa ${ }^{2}$, Francisco \\ Lisboa de Sousa Junior ${ }^{2}$, Lia Jacyara Chaves Pereira ${ }^{3}$, Jefferson da Cruz Silva ${ }^{4}$, Francisca \\ Barros Bezerra ${ }^{5}$
}

\begin{abstract}
${ }^{1}$ Professor do Departamento de Clínica e Cirurgia Veterinária, Universidade Federal do Piauí, Teresina, Brasil.flimavet@hotmail.com ${ }^{2}$ Graduando em Medicina Veterinária, Universidade Federaldo Piaui, Teresina, Brasil.fernandobarbosa2012@hotmail.com; lisboall@hotmail.com ${ }^{3}$ Residente em Clínica Médica e Cirurgia de Cães e Gatos, Hospital Veterinário da Universidade Federal do Piauí, Teresina, Brasil. liajacyara@hotmail.com.br

${ }^{4}$ Aprimorando em Clínica Médica de Cães e Gatos, Hospital Veterinário da Universidade Federal do Piauí, Teresina, Brasil. Jeferson017@hotmail.com.br

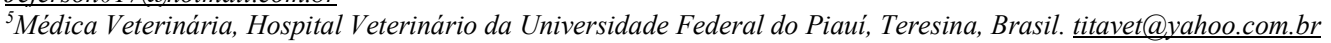
Autor para correspondência,E-mail: tss100g@hotmail.com.br
\end{abstract}

RESUMO. As neoplasias cutâneas são as mais frequentemente encontradas e diagnósticadas em pequenos animais, representando cerca de $30 \%$ dos tumores em cães com cerca de $70-80 \%$ de benignidade nessa espécie. O Lipoma, por sua vez, é considerado uma neoplasia mesenquimal comum benigna originada dos adipócitos ou células gordurosas subcutâneos e ocasionalmente dérmicos. O seu diagnóstico é realizado por meio da observação dos sinais clínicos e exames complementares (hemograma, bioquímica sérica, exames de imagem, e exames de cito e histopatológico). O tratamento cirúrgico por meio da excisão tumoral é um tratamento de eleição, podendo ser associada com radioterapia adjuvante, caso a excisão seja incompleta. O prognóstico para esse tipo de neoplasia pode ser considerado favorável para os lipomas bem circunscritos, sendo reservado para os tumores infiltrativos visto que o percentual de recidivas é alto podendo causar a destruição de tecidos adjacentes. Com base nisso o referido trabalho tem como objetivo relatar o caso clínico de um canino, fêmea, 10 anos de iade, $5,05 \mathrm{~kg}$, Pinscher acometida por um lipoma situado na região cervical esquerda abrangendo a região periauricular do mesmo antímero atendido no Hospital Veterinário Unversitário da Universidade Federal do Piauí.

Palavras chave: Canino, cirurgia, lipoma, neoplasia cutânea

\section{Subcutaneous lipoma covering the cervical and peri-auricular regions of a canine: Case report}

\begin{abstract}
Cutaneous neoplasms are the most frequently found and diagnosed in small animals, accounting for about $30 \%$ of tumors in dogs with about $70-80 \%$ benignity in this species. Lipoma, on the other hand, is considered a benign common mesenchymal neoplasms originating from adipocytes or fat cells subcutaneous and occasionally dermal. Its diagnosis is made through the observation of clinical signs and complementary tests (blood count, serum biochemistry, imaging tests, and cytopathological and histopathological examinations). Surgical treatment through tumor excision is a treatment of choice and may be associated with adjuvant radiotherapy if excision is incomplete. The prognosis for this type of neoplasia can be considered favorable for the well circumscribed lipomas, being reserved for the infiltrative tumors since the percentage of relapses is high and can cause the destruction of adjacent tissues. Based on this, the objective of this study is to report the clinical case of a female canine, 10 years old, $5.1 \mathrm{~kg}$, Pinscher affected by
\end{abstract}


a lipoma located in the left cervical region covering the peri-auricular region of the same antimer attended at the University Veterinary Hospital of the University Federal University of Piauí.

Keywords: Canine, surgery, lipoma, cutaneous neoplasia

\section{Lipoma subcutâneo cubriendo la región cervical periférica auricular de un canino: Reporte de un caso}

RESUMEN. Las neoplasias cutáneas son comúnmente encontrados e diagnosticadas en la clínica de pequeños animales, representando aproximadamente el 30\% de los tumores en perros con alrededor del $70-80 \%$ de benignidad esa especie. El Lipoma, a su vez, es considerado como una neoplasia mesenquimal común benigna, originada de los adipocitos o células grasas subcutáneas y de vez en cuando dérmicas. El diagnóstico se realiza mediante la observación de los signos clínicos y pruebas complementares (hemograma, bioquímica sérica, exámenes de imagen y estudio de cito e histopatología). El tratamiento quirúrgico por medio de la de la escisión del tumor es un tratamiento de elección y puede ser asociado con radioterapia adyuvante, caso la escisión sea incompleta. El pronóstico para este tipo de cáncer puede ser considerado favorable para los lipomas bien circunscritos, siendo reservado para los tumores infiltrativos visto que el porcentaje de reincidenia es alto puediendo causar la destrucción de tejidos adyacentes. Com base en eso el presente trabajo tiene como objetivo reportar el caso clínico de un canino, hembra, 10 años, 5,1 kg Pinscher afectada por un lipoma localizado en la región cervical izquierda cubriendo la región periférica auricular del mismo antímero asistido en el Hospital Veterinario Universitario de la Universidad Federal do Piauí

Palabras clave: Cirugía, lipoma, cáncer de piel canina

\section{Introdução}

As neoplasias cutâneas são as mais frequentemente encontradas e diagnósticadas em animais na rotina de clínicas e hospitais veterinários, representando cerca de $30 \%$ dos tumores em cães com cerca de $70-80 \%$ de benignidade nessa espécie (Paranhos, 2014).

A etiologia da maioria dos tumores cutâneos é desconhecida, porém sabe-se que alguns agentes externos e biológicos exercem um papel importante no desenvolvimento de tais neoplasias, sendo os mais comuns a radiação ultravioleta do tipo $\mathrm{B}$, viroses, predisposição genética, fatores hormonais, imunossupressão, lesões crônicas (pós-vacinais, térmicas), carcinogênese química, lesões cutâneas atróficas, exposição à radiação, fornecimento de dieta caseira, dentre outros (Slatter, 2007, Daleck et al., 2008, Gschwendtner, $\underline{2015)}$.

As características de invasividade e o potencial para ocasionar recidiva local e metástase, estão intimamente ligadas ao que especialistas da área chamam de comportamento biológico de um tumor (Gschwendtner, 2015, Slatter, 2007) e a partir deste pode-se classificar as neoplasias cutâneas em duas amplas categorias, as de tumores primários que tem origem na pele e no subcutâneo e os secundários constituídos pelas metástases de pele (Daleck et al., 2008).

O lipoma, por sua vez, é considerado uma neoplasia mesenquimal comum benigna originada dos adipócitos ou células gordurosas subcutâneos e ocasionalmente dérmicos, sendo responsáveis por cerca de $16 \%$ das neoplasias mesenquimatosas que afetam os caninos (Birchard and Sherding, 2008, Paranhos, 2014).

Os lipomas, em sua grande maioria podem ocorrer como massas únicas ou múltiplas de crescimento lento, as quais são facilmente curadas por meio de excisão cirúrgica, sem a necessidade de associação com um tratamento quimioterápico. Todavia, os lipomas infiltrativos, embora benignos, são mais difíceis de serem removidos, exigindo um número maior de excisões. Estes tumores se localizam com maior frequência sobre o tórax, esterno, abdômen e membros proximais dos cães. Essas massas são geralmente subcutâneas, bem circunscritas (embora não necessariamente bem encapsuladas), flutuantes, moles e algumas vezes multilobuladas (Birchard and Sherding, 2008, Gschwendtner, 2015). 
Apesar de ser tida como uma tumoração de carater benigno, não apresentando risco iminente a vida do animal, sua localização anatômica pode vir a causar problemas futuros ao bem estar dos mesmos, pois a massa tumoral pode crescer exageradamente e causar desconforto, podendo ainda ulcerar gerando um quadro de dor (Gschwendtner, 2015).

Quanto aos fatores epidemiológicos, nota-se que os lipomas são mais comuns em cães e mais raros em gatos, sendo as fêmeas caninas castradas e idosas aparentemente mais acometidas, além disso, a maioria dos animais apresentam essas tumorações com idade média de 8-8,6 anos, podendo a obesidade também ser um fator prédisponente (Birchard and Sherding, 2008, Paranhos, 2014, Gschwendtner, 2015).

Durante o exame clínico do animal, mais especificamente, na etapa de exame físico, por meio da inspeção e palpação, o médico veterinário pode fazer o diagnóstico presuntivo de um tumor de pele. Todavia, em alterações cutâneas que apresentam lesões múltiplas é de fundamental importância que o mesmo institua o diagnóstico diferencial com outras alterações dermatológicas, como por exemplo, lesões inflamatórias, imunomediadas, granulomatosas e etc, sendo importante também, determinar o local das lesões, solicitar os exames hematológicos, bioquímicos, de imagens (Raios-x e Ultra-sonografia), biópsias aspirativas, incisionais e excisionais, para que ocorram as avaliações cito e histopatológicas, sendo estes últimos essenciais para a determinação do tipo celular neoplásico, além de permitirem a definição e o estadiamento do tumor (Wellman, 1996, Guedes et al., 1997, Daleck et al., 2008, Gschwendtner, 2015).

Os tumores pequenos, bem delimitados e de crescimento lento devem ser acompanhados constantemente a fim de avaliar o seu crescimento e evolução. Caso não haja nenhuma alteração significativa no aspeto das lesões, o tratamento cirúrgico não é necessário. O tratamento cirúrgico, por meio da excisão tumoral é um tratamento de eleição para situações estéticas ou para tumores de crescimento acelerado. Os lipomas infiltrativos, por sua vez, devem ser tratados com uma cirurgia agressiva precoce, podendo ser associada com radioterapia adjuvante, caso a excisão seja incompleta (Paranhos, 2014).

O prognóstico para esse tipo de neoplasia pode ser dado em duas configurações, pois pode ser considerado favorável para os lipomas bem circunscritos, sendo reservado para os tumores infiltrativos visto que o percentual de recidivas é alto podendo causar a destruição dos tecidos adjacentes (Paranhos, 2014).

\section{Relato de caso}

No Hospital Veterinário Universitário (HVU) da Universidade Federal do Piauí - UFPI, foi atendido um canino, fêmea, 10 anos de idade, 5,1 $\mathrm{kg}$, da raça Pinscher. Ao atendimento a proprietária relatou (queixa principal) que $\mathrm{o}$ animal vinha apresentando um aumento de volume na região cervical esquerda, o qual surgiu há alguns anos e vinha se desenvolvendo lentamente. Animal encontrava-se ativo, em estado de alerta. Comendo e bebendo normalmente, sem vômito ou diarreia, com diurese e defecação normais. Houve ainda o relato por parte da tutora que o animal possuia seu quadro de vacinação e vermifugação em dias, porém a mesma fazia uso de diclofenaco pomada sobre a região do aumento de volume, além da administração de enrofloxacina prescrita por outro médico veterinário.

Ao exame físico do animal, a médica veterinária responsável pelo caso observou os parâmetros fisiológicos dentro da normalidade, apresentando temperatura retal em torno de 39,0 ${ }^{\circ} \mathrm{C}$, e escore corporal 4 (sobrepeso com costelas, coluna e ossos pélvicos dificilmente palpáveis, ausência de cintura, marcado acumulo de gordura abdominal, sobre a coluna e na base da cauda), mucosas normocoradas, linfonodos palpáveis, com aumento de volume significativo na região cervical esquerda se estendendo à região periauricular, podendo-se notar uma massa de consistência mole e flutuante (Figura 1). $\mathrm{O}$ animal não apresentava ectoparasita e nenhuma outra alteração sistêmica.

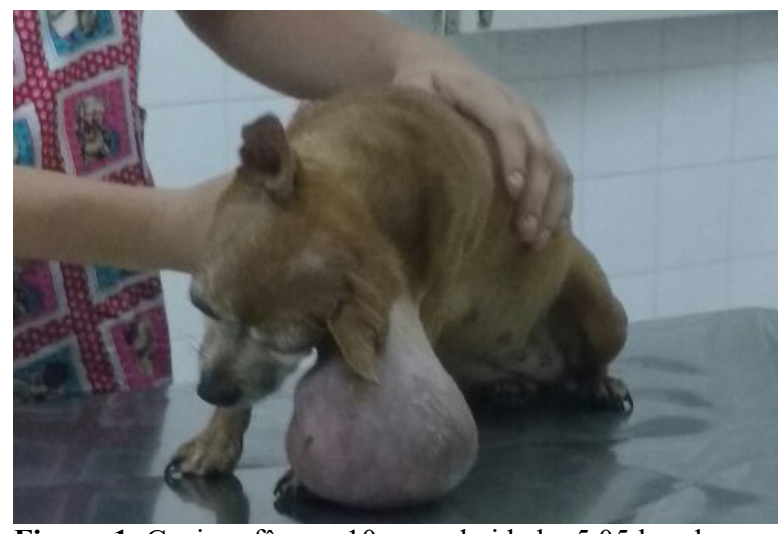

Figura 1. Canino, fềmea, 10 anos de idade, $5,05 \mathrm{~kg}$, da raça Pinscher atendida no HVU-UFPI (fonte: Arquivo pessoal) 
Após a avaliação clínica do animal fez-se a solicitação de alguns exames complementares que viriam auxilíar na suspeita diagnóstica, sendo eles: Hemograma (Eritrograma + Leucograma), Bioquímica Sérica (Renal e Hepática), Exames Cito e Histopatológicos (Biópsia simples) e exame Radiográfico (regiões de crâneo e tórax).

No hemograma não se observou alterações relevantes ao caso, apenas uma discreta linfocitose relativa (42\% - Valores de Referência: $12-30 \%$. Laboratório de patologia clínica-HVU/UFPI.), além disso a bioquímica sérica também apresentou-se sem alterações, uma vez que todos os valores de Uréia, creatinina, ALT, FA, GGT, proteína total, globulinas, albumina, encontravamse dentro das faixas de normalidade.

Ao exame citológico pode-se notar a presença de adipócitos e células inflamatórias. Sugerindose histopatológico para confirmação, sendo este ultimo realizado após a excisão cirúrgica do tumor, onde foi coletado um fragmento de pele pilosa com massa de aproximadamente 1,1 x 8,5 x $5,5 \mathrm{~cm}$, de coloração brancacenta, consistência firme e untuoso ao corte, chegando-se ao diagnóstico de Lipoma.

No que diz respeito aos exames radiográficos de crânio, concluiu-se que não havia evidência de presença de fratura; as estruturas ósseas encontravam-se sem alterações; não havendo características de ossificação patológica e nem presença de luxação, bolhas timpânicas delgadas, seios nasais com padrão turbinado normal, na região torácica notou-se os campos pulmonares sem alterações, não havendo presença de gás no esôfago torácico, silhueta cardíaca definida, trajeto traqueal sem anormalidades, câmaras cardíacas discretamente abauladas, VHS 10,5 (Prancha 1).
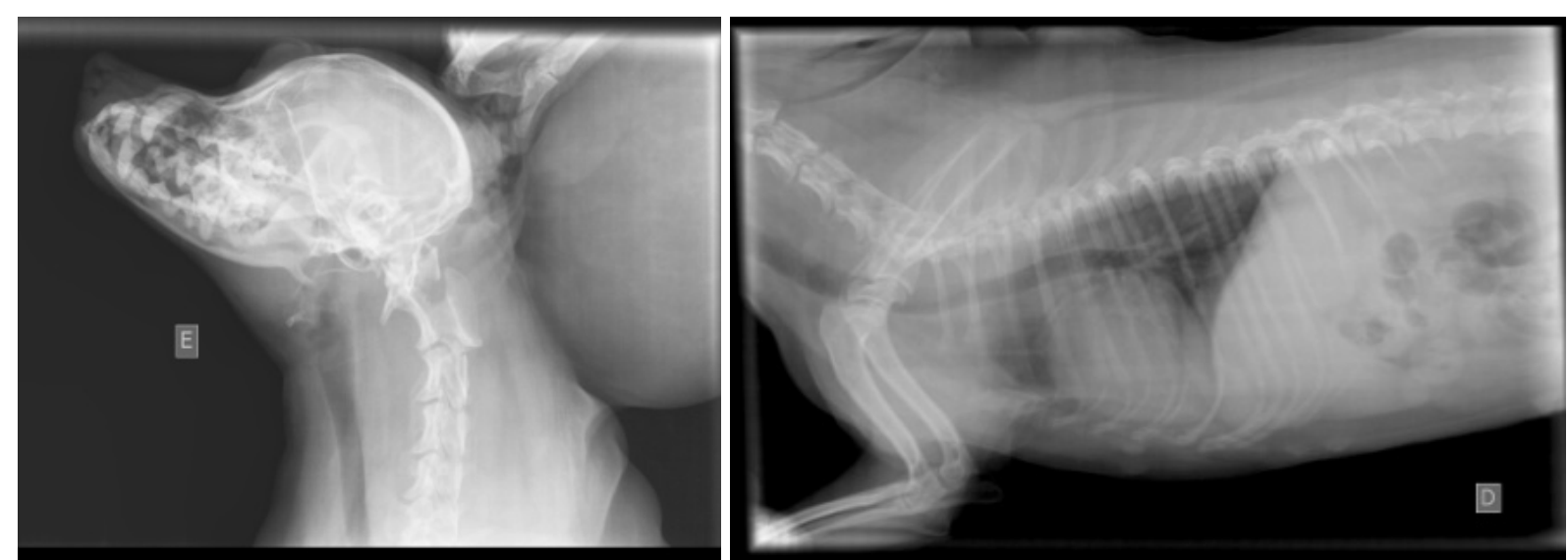

Prancha 1. Radiografias do crânio e tórax de um canino, fêmea, 10 anos, 5,1 kg, Pinscher, atendida no HVU - UFPI. Fonte: Setor de diagnóstico por imagem (HVU - UFPI).

O tratamento de eleição foi o cirúrgico (Nodulectomia/ Excisão cirúrgica do tumor). Após a consulta o animal retornou junto a sua proprietária para casa e no dia anterior à data da cirurgia (pré-agendada), retornou ao HVU para ser internada, como manda as normas do hospital (Todos os animais que forem ser submetidos à procedimentos cirúrgicos devem ser internados no dia anterior a realização da cirurgia). Durante este período a médica veterinária responsável pelo caso prescreveu: Solução Fisiológica 0,9\% (EV) infusão de forma lenta na veia cefálica; Tramadol (4 mg/kg, IM, TID); Cefalotina (20 mg/kg, EV, BID); Meloxicam 0,2\% (0,1 mg/kg, SC, SID).

Além da medicação o animal foi submetido a um jejum sólido de aproximadamente 12 horas e a um hídrico de \pm 6 horas, obedecendo assim os pré- requisitos básicos para a realização de um bom procedimento anestésico-cirúrgico.

$\mathrm{Na}$ data da cirurgia, foi realizada a administração da medicação pré-anestésica (Midazolam - 0,3 mg/kg e Morfina - 0,4 mg/kg IM), passados o período de 10-15 minutos, realizou-se a cateterização da veia cefálica do animal afim de manter uma via de acesso para a administração de medicamentos, além disso realizou-se a tricotomia da região a ser cirurgiada e uma limpeza prévia da mesma, com cloridrato de clorexidine a $2 \%$.

Em seguida o animal foi conduzido ao centro cirúrgico onde recebeu a medicação de indução anestésica (Propofol - 3mg/kg, IV lento), sendo posteriormente entubado com uma sonda endotraqueal e mantido em plano anestésico sob 
anestesia inalatória com isoflurano em um circuito seme-fechado. Ademais, no período transoperatório foi realizada a administração de cefalotina $(30 \mathrm{mg} / \mathrm{kg})$, meloxicam $(0,2 \mathrm{mg} / \mathrm{kg})$ e no pós imediato tramadol $(4 \mathrm{mg} / \mathrm{kg}, \quad \mathrm{IM})$ concomitante a administração de lidocaína sem vaso sobre a região a ser suturada.

Após a indução e estabelecimento do plano anestésico, os cirurgiões realizaram a antissepsia no local da incisão, assim como também em toda a região do tumor, para tal procedimento foram utilizadas, gluconato de clorexidine a $2 \%$ e clorexidine alcoólica, respectivamente. Terminado tal procedimento e com o aval positivo do anestesista responsável, iniciou-se a cirurgia. $\mathrm{O}$ acesso cirúrgico se deu pelas margens do tumor, fazendo-se uma incisão com a lâmina de bisturi em forma elíptica circundando-o por inteiro, a medida que essa ia sendo feita, realizava-se divulsão da pele e a ligadura de vasos calibrosos presentes na região. Após a incisão continuou-se a divulsionar o tecido subcurtânea até a exposição completa do tumor, culminando com sua excisão, uma vez que, o mesmo não era de carater invaginante. Retirado o nódulo, fez-se a chamada redução da borda em orelha, pois como a pele estava muito distendida, ocorreria a formação de uma dobra cutânea que dificultaria a sutura da pele, $\operatorname{logo}$ após iniciou-se a aproximação subcutânea, que foi realizada com fio de Poliglactina 910, 2-0 em pontos simples contínuos e posteriormente a sutura de pele com pontos isolados simples com fio mononylon 2-0 (Prancha 2).

Após o procedimento cirúrgicoo animal permaneceu internado por dos dias, e durante esse período este recebeu a mesma medicação que foi administrada durante a internação, além da realização de curativos na região cirurgiada, ao receber alta, foi realizada a prescrição dos seguintes medicamentos para o tratamento póscirúrgico: uso oral (Amoxicilina trihidratada e Clavulanato de potássio (Synulox) $50 \mathrm{mg}$ (1 comp. VO, BID/ 10 dias); Meloxicam 0,5 mg ( 1 comp., VO, SID/3 dias); Cloridrato de Tramadol $40 \mathrm{mg}$ ( $1 / 2$ comp,VO, TID, 3dias); uso tópico (Rifocina Spray - Aplicar sobre a ferida cirúrgica após a limpeza, 2 vezes por dia até a cicatrização) e Utilização de colar Elisabetano até retirada dos pontos.

Como o animal era proveniente de outra cidade do sul do Estado do Piauí, tornou-se inviável, segundo a proprietária, o retorno á consulta médica para o acompanhamento do caso. Porém a mesma via rede social, relatou à médica veterinária responsável que o seu animal passava bem e não apresentava nenhuma outra alteração.

\section{Discussão}

Segundo Meuten (2002) e Paranhos (2014) o lipoma, é considerado uma neoplasia mesenquimal comum benigna originada dos adipócitos ou células gordurosas subcutâneas e ocasionalmente dérmicas, sendo tumores bem circunscritos, encapsulados, massas macias, de coloração esbranquiçadas à amareladas indistinguíveis de tecido adiposo normal e móveis, o que vai de encontro a algumas características apresentadas pelo tumor encontrado na paciente do caso clínico apresentado, o que direcionou a clínica ao suposto diagnóstico de lipoma, que por sua vez, foi confirmado após o resultado do exame histopatológico.

Existem alguns autores que afirmam que muitas vezes o diagnóstico de lipoma, possa representar apenas uma alteração no metabolismo dos adipócitos bem como uma hiperplasia nodular, ao invés de uma neoplasia propriamente dita, porém como esta alteração celular muitas vezes se apresenta como um nódulo e levam muitos profissionais a inferir um diagnóstico de neoplasia (Gross et al., 2009, Goldschmidt and Hendrick, 2008).

A maioria dos lipomas são massas de crescimento lento (Gschwendtner, 2015) e se apresentam em animais com faixa etária média de 8,7 anos como afirmam Bento et al. (2013), já Meirelles et al. (2010) em seus estudos obteviveram resultados de idade média em torno de 7,6 anos e Goldschmidt and Shofer (1992) encontraram maior ocorrência em animais com idade em torno de 8 anos, sendo as fêmeas consideradas os animais mais predispostos, o que encontra-se em consonância ao caso de lipoma encontrado, além disso, pode-se afirmar que o tumor encontrado na paciente atendida no HVUUFPI, no que diz respeito ao crescimento tumoral, obedece os relatos de Gschwendtner.

Gschwendtner (2015) afirma que animais que se encontram com escore corporal alto, isto é, que possui um quadro de sobrepeso até uma obesidade acentuada, possui maior predisposição ao desenvolvimento de lipomas, porém deve-se atentar para o fato de que animais que se encontram com essas características tendem normalmente a desenvolver acúmulos de gordura 
localizado, que por falta de perícia muitas vezes é confundido com um lipoma.

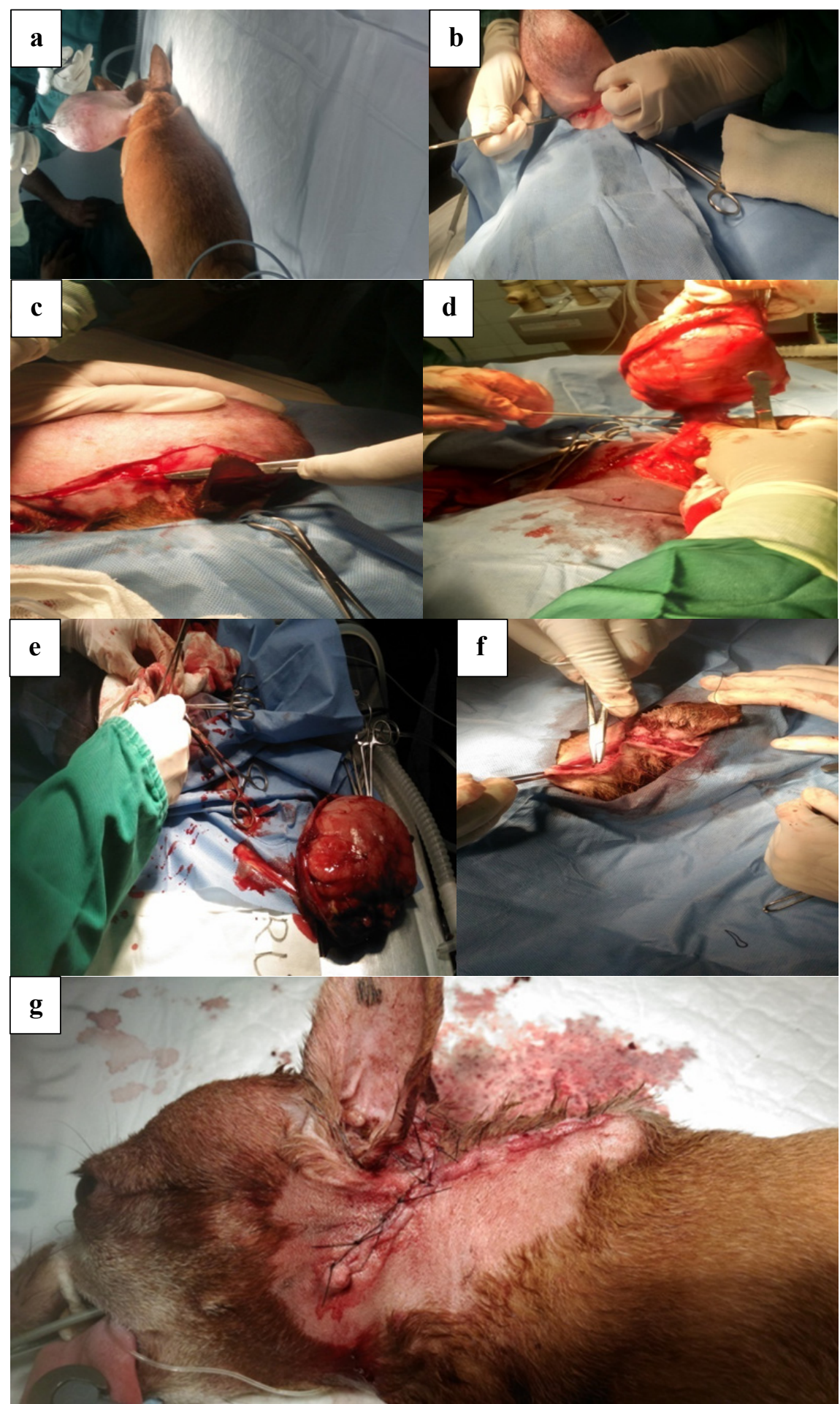

Prancha 2. Acesso cirúrgico: a- Assepsia do campo cirúrgico. b- incisão cutânea e subcutânea. c- ligadura de vasos calibrosos. d-divulsão dos tecidos e exposição do tumor. e- exérese do tumor. f- aproximação do subcutâneo g- sutura de pele. Fonte: Arquivo pessoal.

Quanto a região anatômica da localização do lipoma, Rossetto et al. (2009) concluíram em seus estudos que a região torácica com $22,7 \%$ é a região de maior ocorrência, sendo seguida pelas regiões de abdômen e membros (Hnilica and Patterson,
2011) podendo ocorrer também em outros locais, como por exemplo, na região cervical, porém em proporções não tão significativas.

Baseando-se nos sinais clínicos apresentados pelo animal no momento da consulta e no 
resultado dos exames laboratoriais e de imagem, que por sua vez não apresentaram nenhuma alteração específica, excetuando-se o incômodo apresentado pelo animal em função da presença da grande massa pendular situada na região cervical/peri-auricular, indica-se a benignidade da neoplasia e um forte direcionamento para a suspeita diagnóstica de lipoma, que foi posteriormente confirmado pela realização do exame histopatológico (Fineman, 2004).

A excisão cirúrgica do tumor foi o tratamento de eleição para este caso de lipoma, uma vez que, a mesma é considerada como um procedimento cirúrgico simples, e que apesar do tamanho exagerado da massa tumoral presente, a realização da cirurgia ocorreu sem maiores dificuldades ou complicações, o que é comum para este tipo de neoplasia, além disso, como foi retirada toda a massa tumoral, o prognóstico dado foi favorável (North and Banks, 2009).

Após excisão cirúrgica do nódulo, efetuou-se uma avaliação macroscópica, revelando as dimensões aproximadas de $15 \mathrm{~cm}$ de comprimento com $11 \mathrm{~cm}$ de largura e peso igual a aproximadamente $1,5 \mathrm{~kg}$, sendo então encaminhado para análisehistopatológica, uma vez que, durante o atendimento clínico foi realizado a coleta de material para a análise citológica, entretanto não se obtendo um diagnóstico conclusivo sugeriu-se a realização do exame anteriormente citado.

No que diz respeito à medicação prescrita para a realização do tratamento terapêutico em casa, a antibiótico-terapia a base de amoxicilina trihidratada e clavulanato de potássio (fármaco aminopenicilínico) teve como objetivo a prevenção de futuras infecções da ferida cirúrgica, principalmente por microorganismos Gramnegativos, uma vez que, a amoxicilina penetra mais facilmente na parede celular dessas bactérias, atuandocomo agente bactericida, no que refere-se a utilização de um antiinflamatório não esteroidal, neste caso o meloxicam, o mesmo além da ação antiinflamatória, apresenta uma ação analgésica, pois ocorre a inibição da COX-1 e COX-2, em proporções geralmente diferentes, inibindo também a liberação de prostaglandinas, prostaciclinas e tromboxanos, que são importantes mediadores da inflamação e da dor, efeito este potencializado pelo analgésico opioide Cloridrato de tramadol (Andrade, 2008).

Para uso tópico a médica veterinária prescreveu rifocina spray, medicamento a base de rifamicina um antibiótico bactericida, que inibe a RNA-polimerase dependente de DNA, prevenindo a iniciação da síntese de RNA, tendo ação principal contra microorganimos Grampositivos e micobactérias (Andrade, 2008).

\section{Conclusão}

As neoplasias cutâneas são as mais frequentemente encontradas e diagnósticadas em pequenos animais sendo o lipoma uma das de maior ocorrência, correspondendo a cerca de $16 \%$ das neoplasias de pele e/ou subcutânea em caninos, sendo facilmente diagnosticado. $\mathrm{O}$ tratamento por meio da excisão cirúrgica tem resultados satisfatórios e na maioria dos casos não necessitando de quimioterapia adjuvante, com tudo, como o animal do caso anteriormente descrito, era proveniente de outra cidade do sul do Estado, tornou-se inviável, segundo a proprietária o retorno á consulta médica para a retirada dos pontos e acompanhamento do caso. Porém a mesma via rede social, relatou à médica veterinária responsável que o seu animal passava bem e não apresentava nenhuma outra alteração, sendo o animal encaminhado para posterior acompanhamento por outro profissional residente na região.

\section{Referências Bibliográficas}

Andrade, S. F. 2008. Manual da Terapêutica Veterinária. Rocca, São Paulo.

Bento, M. S., Chamelete, M. O. \& Dantas, W. F. M. 2013. Diagóstico clínico e histopatológico de neoplasmas cutâneos em cães e gatos atendidos na rotina clínica do hospital veterinário da Univiçosa. ANAIS SIMPAC, 5.

Birchard, S. J. \& Sherding, R. G. 2008. Manual Saunders: clínica de pequenos animais, São Paulo.

Daleck, C. R., De Nardi, A. B., Rodigheri, S. M. \& Motta, F. R. 2008. Neoplasia do sistema urinário. Roca, São Paulo.

Fineman, L. S. 2004. Tumores da pele e do tecido subcutâneo em cães e gatos. In: Roshental, R. C. (ed.) Segredos em oncologia veterinária. Artmed, Porto Alegre.

Goldschmidt, M. H. \& Hendrick, M. J. 2008. Tumors of the skin and soft tissues. In: Meuten, D. J. (ed.) Tumors in Domestic Animals, Fourth Edition. Iowa State Press, Iowa. 
Goldschmidt, M. H. \& Shofer, F. S. 1992. Skin tumors of the dog and cat. Pergamon Press Ltd, Oxford.

Gross, T. L., Ihrke, P. J., Walder, J. E. \& Affolter, K. V. 2009. Doenças de pele do cão e do gato: diagnóstico clínico e histopatológico. Roca, São Paulo.

Gschwendtner, G. 2015. Relatório de estágio e revisão bibliográfica relacionando lipoma e obesidade em cães.

Guedes, R. M. C., Nogueira, R. H. G. \& Tudury, E. A. 1997. Diagnóstico citológico de lesões proliferativas e inflamatórias através da técnica de punção de tecidos com agulha fina. Hora Veteterinária, 96, 15-21.

Hnilica, K. A. \& Patterson, A. P. 2011. Small animal dermatology: a color atlas and therapeutic guide. Elsevier Health Sciences.

Meirelles, A. E. W. B., Oliveira, E. C., Rodrigues, B. Á., Costa, G. R., Sonne, L., Tesser, E. S. \& Driemeier, D. 2010. Prevalência de neoplasmas cutâneos em cães da Região Metropolitana de Porto Alegre, RS: 1.017 casos (2002-2007). Pesquisa Veterinaria Brasileira, 30, 968-973.

Meuten, D. J. 2002. Tumors of the skin and soft tissues. Iowa Satate Press, Iowa.

North, S. \& Banks, T. 2009. Tumours of skin and subcutaneous tissues. Sauders Elsevier, London.
Paranhos, C. A. 2014. Neoplasias cutâneas caninas: um estudo descritivo de 4 anos. Medicina Veterinária. Universidade de Trásos-Montes e Alto Douro, Vila Real.

Rossetto, V. J. V., Moreno, K., Grotti, C. B., Reis, A. C. F. \& Bracarense, A. P. F. R. L. 2009. Frequência de neoplasmas em cães diagnosticados por exame citológico: estudo retrospectivo em um hospital-escola. Semina: Ciências Agrárias, 30, 189-200.

Slatter, D. H. 2007. Manual de cirurgia de pequenos animais. Manole, São Paulo.

Wellman, M. L. 1996. Cytology and the diagnosis of neoplasia. Proceedings from the Tenth Annual Kal Kan Symposium for the Treatment of Small Animal DiseasesThe Ohio State University. Ohio.

\section{Article History:}

Received 9 January 2017

Accepted 25 January 2017

Available on line 9 February 2017

License information: This is an open-access article distributed under the terms of the Creative Commons Attribution License 4.0, which permits unrestricted use, distribution, and reproduction in any medium, provided the original work is properly cited. 